\title{
Does the oxygen reserve index play a role in oxygen therapy?
}

\author{
Shingo Kawashima ${ }^{1} \cdot$ Hiroyuki Kinoshita ${ }^{1,2} \mathbb{C}$
}

Received: 12 October 2021 / Accepted: 14 October 2021

(c) The Author(s) under exclusive licence to Japanese Society of Anesthesiologists 2021

\section{To the Editor:}

We read the review article by Ishida et al. with interest [1]. They elegantly summarized the Oxygen Reserve Index (ORi), which indicates a relative oxygen partial pressure dissolved in arterial blood $\left(\mathrm{PaO}_{2}\right)$ in the range of 100-200 $\mathrm{mmHg}$ shown as indices from 0 to 1 [1]. Ishida et al. [1] mentioned that normoxia is where $\mathrm{PaO}_{2}$ is about $100 \mathrm{mmHg}$ (Fig. 2 in the Ref. [1]). However, we are somewhat confused regarding their definition of normoxia when we take a recent trend of oxygen therapy in patients with advanced diseases into account. A systematic review and meta-analysis included 25 randomized controlled trials that enrolled 16,037 patients with sepsis, critical illness, stroke, trauma, myocardial infarction, cardiac arrest, and patients who had emergency surgery [2]. The analysis examined whether oxygen strategy affects the patients' outcome, and the results indicated that supplemental oxygen is unfavorable above the oxygen saturation $\left(\mathrm{SpO}_{2}\right)$ range of $94-96 \%$ in severely ill patients [2]. A New Zealand study group has documented in adult patients undergoing mechanical ventilation in the intensive care unit that the use of conservative oxygen therapy, in which a $\mathrm{SpO}_{2}$ was maintained in a range of $90-97 \%$, as compared with standard oxygen therapy, did not significantly affect the number of ventilator-free days [3]. The results suggest that such a conservative oxygen therapy is sufficient for managing patients undergoing mechanical ventilation. A multicenter, prospective, randomized, controlled trial evaluated the role of oxygen administration ( 8

This comment refers to the article available online at https://doi. org/10.1007/s00540-021-02938-4.

Hiroyuki Kinoshita

hkinoshi@krc.biglobe.ne.jp

1 Department of Anesthesiology and Intensive Care, Hamamatsu University School of Medicine, Hamamatsu, Japan

2 Department of Anesthesiology, Institute of Biomedical Sciences, Tokushima University Graduate School, 3-18-15 Kuramoto, Tokushima 770-8503, Japan
$\mathrm{L} / \mathrm{min}$ ) in patients with ST-elevation-myocardial infarction diagnosed on a 12-lead electrocardiogram [4]. Compared with no oxygen therapy demonstrating $\mathrm{SpO}_{2}<100 \%$, the supplemental oxygen therapy increased early myocardial injury and was associated with larger myocardial infarct size assessed at 6 months [4]. According to the study results, supplying oxygen therapy appears unnecessary and even involves risks since most cardiovascular patients are not hypoxemic at baseline, and thus, normoxia is currently defined as $\mathrm{SpO}_{2} \geq 90 \%$ in the disease population [5]. All of the above recent studies sufficiently indicate that $\mathrm{PaO}_{2}<100 \mathrm{mmHg}$, which is outside of the ORi's range, is critical to monitor to avoid detrimental effects caused by hyperoxia in the current oxygen therapy. Therefore, further studies will be required to verify the ORi's usefulness in patients with advanced diseases.

\section{References}

1. Ishida Y, Okada T, Kobayashi T, Uchino H. ORi ${ }^{\mathrm{TM}}$ : a new indicator of oxygenation. J Anesth. 2021;35:734-40.

2. Chu DK, Kim LL-H, Young PJ, Zamiri N, Almenawer SA, Jaeschke R, Szczeklik W, Schünemann HJ, Neary JD, Alhazzani W. Mortality and morbidity in acutely ill adults treated with liberal versus conservative oxygen therapy (IOTA): a systematic review and meta-analysis. Lancet. 2018;391:1693-705.

3. ICU Rox Investigators the Australian and New Zealand Intensive Care Society Clinical Trials Group. Conservative oxygen therapy during mechanical ventilation in the ICU. N Engl J Med. 2020;382:989-98.

4. Stub D, Smith K, Bernard S, Nehme Z, Stephenson M, Dip G, Bray JE, Cameron P, Barger B, Ellims AH, Taylor AJ, Meredith IT, Kaye DM, on behalf of the AVOID Investigators. Air versus oxygen in ST-segment-elevation myocardial infarction. Circulation. 2015;131:2143-50.

5. Hofmann R, James SK. Routine oxygen supplementation in acute cardiovascular disease: the end of a paradigm? Circulation. 2018;137:320-2.

Publisher's Note Springer Nature remains neutral with regard to jurisdictional claims in published maps and institutional affiliations. 